\title{
Inhibition of Very-Long-Chain Fatty Acid Formation by Indanofan, 2-[2-(3-Chlorophenyl)oxiran-2-ylmethyl]-2-ethylindan-1,3-dione, and Its Relatives
}

Hideomi Takahashi ${ }^{a}$, Jochen Schmalfuß ${ }^{\mathrm{a}}$, Aiko Ohki ${ }^{\mathrm{a}}$, Akemi Hosokawa ${ }^{\mathrm{b}}$, Akira Tanaka $^{\mathrm{c}}$, Yukiharu Sato ${ }^{\mathrm{a}}$, Bernd Matthes ${ }^{\mathrm{d}}$, Peter Böger*,d and Ko Wakabayashi*,a

a Graduate School of Agricultural Science, Tamagawa University, Machida-shi, Tokyo 194-8610, Japan

b Mitsubishi Chemical Co., Ltd., Specialty Chemicals Research Center, 1000 Kamoshida-cho, Aoba-ku, Yokohama 227-8502, Japan

c Showa Pharmaceutical University, Machida-shi, Tokyo 194-8843, Japan

d Lehrstuhl für Physiologie und Biochemie der Pflanzen, Universität Konstanz, D-78457 Konstanz, Germany

* Authors for correspondence and reprint requests

Z. Naturforsch. 57c, 72-74 (2002); received October 5, 2001

Rice Herbicides, Very-Long-Chain Fatty Acids, Tridiphane

Indanofan and its analogs inhibited the elongation of stearoyl- or arachidoyl-CoA by $\left[2-{ }^{14} \mathrm{C}\right]$-malonyl-CoA in leek microsomes from Allium porrum. Although the precise mode of interaction of indanofan at the molecular level is not completely clarified by the present study, it is concluded that indanofan and analogs act as inhibitor of the elongase enzyme involved in de novo biosynthesis of fatty acids with an alkyl chain longer than $\mathrm{C}_{18}$, called very-long-chain fatty acids (VLCFAs). For a strong inhibition of VLCFA formation chloro substituents at the benzene ring and the oxirane group were necessary. Furthermore, the greenhouse test showed strong activity for indanofan and its analogs, and the scores coincided with cell-free elongation inhibition. The cell-free assay, however, failed to indicate any activity for an analog having a methylene instead of the oxirane group, while both Digitaria ciliaris and Echinochloa oryzicola were killed with $1 \mathrm{~kg}$ a.i./ha. This finding cannot be discussed because the applied use rate of $1 \mathrm{~kg}$ a.i./ha is too high to allow for a score differentiation. For high concentrations of this compound additional unknown inhibitory effects may be involved besides fatty acid elongation.

\section{Introduction}

Tridiphane, an oxirane compound, shows phytotoxic activity (Zorner et al., 1986). It conjugates with reduced glutathione (GSH) catalyzed by glutathione $S$-transferase (GST), and the conjugate inhibits the enzyme (Lamoureux and Rusness, 1986). A synergistic effect to atrazine is observed, since this herbicide cannot be detoxified anymore due to lack of GSH and inhibited GST. Tridiphane, however, includes five chlorines in the molecule which prompted researchers to develop oxiranes with less chlorine. Hosokawa et al. (2001) introduced indanofan, a herbicidal oxirane compound, with apparently more favorable environmental properties (for structures see Table I). Indanofan is phytotoxic against gramineous weeds in paddy rice. A $100 \%$ kill for Echinochloa oryzicola was found with 100 to $150 \mathrm{~g}$ a.i./ha.
In this paper, we report on a direct phytotoxic mode of action of both tridiphane and indanofan, namely the inhibition of very-long-chain fatty acid formation by these compounds and some analogs. The mode of action is similar to chloroacetamide herbicides (Matthes et al., 1998).

\section{Materials and Methods}

The cell-free assays of this study are based on the incorporation of $\left[2-{ }^{14} \mathrm{C}\right]$ malonyl-CoA into stearoyl-(C18:0)-CoA or arachidoyl-(C20:0)-CoA, as indicated in Table I. All labeled chemicals were purchased from Amersham, Braunschweig, Germany. Isolated microsomes from leek seedlings were used (for details see Schmalfuß et al., 2000; Takahashi et al., 2001). Indanofan and its analogs were prepared according to Hosokawa et al. (2001). 


\section{Biological test under paddy condition}

Herbicidal activity under paddy condition was evaluated in greenhouse pot tests. At first Digitaria ciliaris and Echinochloa oryzicola were tested with $1.0 \mathrm{~kg}$ a.i./ha. Pots filled with light clay soil were watered to establish a paddy condition with $3 \mathrm{~cm}$ water depth. Weeds were seeded into the soil to less than $1 \mathrm{~cm}$ depth and rice plants were transplanted. The compounds were applied as flowable formulation to the water surface five days after seeding. Three weeks after treatment, herbicidal activities were evaluated and rated by scores 0 to $10(0=$ no effect, $10=$ complete kill $)$. In the second screening Echinochloa oryzicola was tested with a rate of $0.063 \mathrm{~kg}$ a.i./ha. The compounds were ap-

Table I. Inhibition of VLCFA elongation and herbicidal activity by indanofan and its relatives.

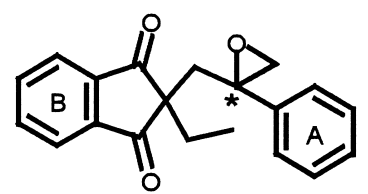

\begin{tabular}{|c|c|c|c|c|c|c|c|}
\hline \multirow[t]{2}{*}{$\begin{array}{c}\text { Compounds } \\
\text { No. }\end{array}$} & \multirow[t]{2}{*}{ Structure } & \multirow{2}{*}{$\begin{array}{c}\begin{array}{c}\text { Digitaria } \\
\text { ciliaris }\end{array} \\
1.0 \mathrm{~kg} / \mathrm{ha}\end{array}$} & \multicolumn{2}{|c|}{$\begin{array}{r}\text { Herbicidal activity } \\
\text { Echinochloa } \\
\text { oryzicola }\end{array}$} & \multicolumn{3}{|c|}{$\begin{array}{c}\text { Inhibition of VLCFA elongation ( } \% \text { of control) } \\
\text { C18:0 <upper row }>\text {, C20:0 < lower row }> \\
\text { Leek }(\text { Allium porrum })\end{array}$} \\
\hline & & & $1.0 \mathrm{~kg} / \mathrm{ha}$ & $0.063 \mathrm{~kg} / \mathrm{ha}$ & $0.1 \mu \mathrm{M}$ & $1 \mu \mathrm{M}$ & $10 \mu \mathrm{M}$ \\
\hline 1 & & 8 & 9 & 8 & $9 \stackrel{-}{ \pm 11)}$ & $43 \stackrel{-}{( \pm 0)}$ & $81 \stackrel{-}{( \pm 1)}$ \\
\hline$\stackrel{2}{\mathbf{2}}$ & & 10 & 10 & 10 & $\begin{array}{c}31( \pm 10) \\
49( \pm 1)\end{array}$ & $\begin{array}{l}44( \pm 6) \\
83( \pm 1)\end{array}$ & $\begin{array}{l}58( \pm 1) \\
95( \pm 1)\end{array}$ \\
\hline 3 & $\begin{array}{c}\text { Indanofan } \\
S \text {-enantiomer }\end{array}$ & 10 & 10 & 10 & $\begin{array}{c}47( \pm 2) \\
-\end{array}$ & $\begin{array}{c}57( \pm 5) \\
-\end{array}$ & $\begin{array}{c}63( \pm 6) \\
-\end{array}$ \\
\hline 4 & & 9 & 10 & 8 & $44 \stackrel{-}{( \pm 1)}$ & $83 \stackrel{-}{( \pm 2)}$ & $94 \stackrel{-}{( \pm 1)}$ \\
\hline 5 & & 5 & 10 & 8 & $46 \stackrel{-}{( \pm 5)}$ & $86( \pm 5)$ & $93( \pm-$ \\
\hline 6 & & 10 & 10 & 5 & $0(\stackrel{-}{ \pm 1})$ & $2( \pm 1)$ & $7( \pm 6)$ \\
\hline $\begin{array}{c}\mathbf{7} \\
\text { (Tridiphane) }\end{array}$ & & 10 & 10 & 7 & $\begin{array}{l}16( \pm 9) \\
12( \pm 9)\end{array}$ & $\begin{array}{l}28( \pm 18) \\
44( \pm 19)\end{array}$ & $\begin{array}{l}53( \pm 1) \\
72( \pm 3)\end{array}$ \\
\hline
\end{tabular}

* Chiral carbon. 
plied ten days after seeding. Four weeks after treatment phytotoxicity was evaluated by a 0 to 10 rating system (Hosokawa et al., 2001).

\section{Results and Discussion}

Inhibition of acyl-CoA elongation using microsomes from leek seedlings

Compounds $\mathbf{1}$ and $\mathbf{7}$ (tridiphane) inhibited C20:0 elongation with an approx. $\mathrm{I}_{50}$ value of $10^{-6} \mathrm{M}(\mathrm{Ta}-$ ble I). The $\mathrm{I}_{50}$ values of compounds 2 (indanofan), 4 and 5 were found around $10^{-7} \mathrm{M}$. Compounds 2 and 7 affected C20:0 elongation more strongly than $\mathrm{C} 18: 0$ elongation, possibly indicating that these compounds inhibited an elongase II more strongly than elongase I (see Schmalfuß et al., 2000 , for the possible existence of two elongases in leek microsomes). It should also be noted that compound $\mathbf{3}$, the $S$-enantiomer of indanofan, inhibits C18:0 elongation somewhat better than no. $\mathbf{2}$, the racemic indanofan. Influence of chirality has also been found with chloroacetamides (Matthes et al., 1998).

Chloro substituents at the benzene ring are important for strong inhibition as well as the oxirane group. Replacement of the latter by a methylene group (compound 6) did not result in an active compound. An additional 4,5-dichlorination at the indandione moiety (compound 5) did not improve activity further. The $\mathrm{I}_{50}$ value for arachidoyl-CoA elongation can be estimated as $10^{-7} \mathrm{M}$ just like that

Böger P., Matthes B. and Schmalfuß J. (2000), Towards the primary target of chloroacetamides-new findings pave the way. Pest Manag. Sci. 56, 497-508.

Hosokawa A., Shike T., Katsurada M., Ikeda O., Minami N. and Jikihara T. (2001), Synthesis and herbicidal activity of indanofan and related 2-(2-phenyloxiran-2ylmethyl)indan-1,3-dione derivatives. J. Pestic. Sci. 26, $41-47$.

Lamoureux G. L. and Rusness D. G. (1986), Tridiphane [2-(3,5-dichlorophenyl)-2-(2,2,2-

trichloroethyl)]oxirane, an atrazine synergist: Enzymatic conversion to a potent glutathione S-transferase inhibitor. Pestic. Biochem. Physiol. 26, 323-342.

Matthes B., Schmalfuß J. and Böger P. (1998), Chloroacetamide mode of action II: Inhibition of very long chain fatty acid synthesis in higher plants. Z. Naturforsch. 53c, 1004-1011. for indanofan. Changing the trichloromethyl group of tridiphane to an indan-1,3-dione moiety increased inhibitory activity about 10 -fold (compare compounds 7 and 4). Compound 1 without any chlorine had about the same activity as compound 7 (tridiphane).

\section{Herbicidal activity and elongation inhibition}

The greenhouse test showed strong activity for compounds 1-5 (Table I). The scores coincided with cell-free elongation inhibition. This was particularly evident with Echinochloa, while the herbicidal effect of compound $\mathbf{5}$ was found somewhat less. Compound $\mathbf{6}$ is considered as an outlier. The cell-free assay failed to indicate any activity while both Digitaria and Echinochloa were completely killed with $1 \mathrm{~kg}$ a.i./ha. This finding cannot be discussed because the use rate of $1 \mathrm{~kg}$ a.i./ha is too high to allow for a score differentiation. Additional unknown inhibitory effects may be involved besides fatty acid elongation inhibition when applied at higher concentrations.

In the greenhouse test a higher phytotoxicity of the indanofan S-enantiomer vs. the racemic one (cpds. 3, 2) could not be found.

\section{Acknowledgements}

The authors are grateful to Dr. Toshiyuki Chikuma, Showa Pharmaceutical University for competent advice.
Schmalfuß J., Matthes B., Knuth K. and Böger P. (2000), Inhibition of acyl-CoA elongation by chloroacetamide herbicides in microsomes from leek seedlings. Pestic. Biochem. Physiol. 67, 25-35.

Takahashi H., Ohki A., Kato S., Tanaka A., Sato Y., Matthes B., Böger P. and Wakabayashi K., (2001), Inhibition of very-long-chain fatty acid biosynthesis by 2-chloro- $N$-(3-methoxy-2-thenyl)-2',6'-dimethylacetanilide thenylchlor, and its analogs. Pestic. Biochem. Physiol., in press.

Zoner P. S., Markley L. D., Stafford L. E., Ray P. G. and Renga J. M., (1986), Physiological mechanism responsible for triazine synergism with pro-epoxides of tridiphane herbicides. Abstract, no. 7D-09, 6th. Intern. Congr. Pestic. Chem., Ottawa. 